\title{
Objects, Components and the Virtual Enterprise
}

\author{
P.A. Nixon \\ Computer Science \\ Trinity College Dublin \\ Ireland \\ Paddy.Nixon@cs.tcd.ie
}

\author{
S.A. Dobson \\ Computer Science \\ Trinity College Dublin \\ Ireland \\ Simon.Dobson@cs.tcd.ie
}

\begin{abstract}
We are currently witnessing a convergence of several threads of technology and business imperatives. The idea of a virtual enterprise (VE) - a business built from both organizationally and geographically distributed units - is becoming an area of increasing interest to both computer scientists and business people. The Objects, Components and the Virtual Enterprise workshop at OOPSLA 98 investigated the role of Object/Component analysis, design and programming in the realization of the VE. The workshop addressed topics including lifecycle models, case studies, HCI, object renaming, and software architectures VEs.
\end{abstract}

\section{Background}

We are currently witnessing a convergence of several threads of technology and business imperatives. The idea of a virtual enterprise - a business built from both organizationally and geographically distributed units - is becoming an area of increasing interest to both computer scientists and business people.

Virtual enterprises are becoming feasible on account of a number of technology phenomena including CORBA, the World Wide Web, Java and component-based software; they are becoming attractive because of business trends such as downsizing and outsourcing. Set against these positive factors are a number of disincentives, including exposing key business processes to the hostile Internet, the extra complexities of cross-border contracts, and the fluidity of the software marketplace.

From a business perspective building a virtual enterprise involves contracts, cross-organizational management and statutory obligations. From a technical perspective, it involves confronting problems such as heterogeneity, distribution, authentication, privacy, and auditing. While each of these technologies is being applied piecemeal to address one more of the business imperatives resulting in "creeping" virtual enterprises - an overall technical vision for their seamless integration remains elusive. It is now time to ask the questions:

- is object technology the right way to implement a virtual enterprise?

- if so, what technologies are appropriate?

- how should they be composed?

- and how should they be driven by the underlying business process? 
The aim of the workshop was to bring together a complementary group of workers in the following fields:

- those building frameworks or infrastructures for virtual enterprises;

- those investigating the object/component methodologies and processes (both software and managerial) for constructing virtual enterprises; and

- those with experience in specific virtual enterprises.

The intention was to facilitate the exchange of ideas between those working on the general problems of dynamic component integration and those with specific practical problems to solve or experiences to offer. The workshop brought together practicing software engineers and researchers in workflow, component-based software and software methodologies. The specific targets for the workshop were:

- to identify those factors - technological, managerial and political - which impede the creation of virtual enterprises;

- to identify any new business models which emerge from improving business communication and interaction; and

- to draw a road map of projected future developments, to aid the development of strategies for deploying virtual enterprises.

\section{From business to implementation}

The quality of submitted papers was extremely high, and covered a wide range of interests - from underlying technologies, through infrastructure and development methods, up to business-level organisational concerns. We divided the presentations into three sessions: business drivers, design issues, and technological futures.

\section{Business drivers}

The area in which virtual enterprises may have most impact is among the small-to-medium sized enterprises (SMEs) that lack the resources necessary to construct their own distributed infrastructures from scratch. Raghbir Singh's presentation of the VENICE project was thus very welcome, as it included a user survey conducted amongst SMEs into how they saw VEs affecting their business.

While the advantages of VEs (flexibility, rapid response, etc) were well supported, a number of concerns to do with management fragmentation and social isolation were identified: aspects which, whilst perhaps less obvious to technology developers, are critical to the adoption of their technology. There is a keen need for informal meetings, especially in the initial stages of projects, again perhaps not well supported by current CSCW tools.

Trinity College's paper focussed on the interface between software design and business contexts, to identify any weaknesses in current design methods. A simple case study involving three 
stakeholder organizations within a single use case was elaborated using a standard analysis method, leading to a number of technically acceptable object models.

From a business standpoint, however, each model suffered from critical weaknesses in the area of information disclosure - for the simple reason that current analysis methods foster a view of software in which all components in a system are equally trusted and controlled. By taking the notion of trust domains and using it as a basis for re-analyzing the models, it was possible to derive a compromise model which reflected the differences and evolution in trust relationships between participating organizations. A more general conclusion was the need to capture and reflect trust relationships adaptively throughout a VE's information system.

The third business drivers paper came from Mike Freiling, a consultant intimately concerned with how a VE would be presented to customers. The key place of trust and credibility emerged strongly, especially with regard to the organizational stability and established track records desired by clients. Simply put, virtualising a business internally does not affect the fundamental relationship between that business and its clients. In many ways this strikes against the common software notions of abstraction and encapsulation, which can damage trust: disclosure of internal policies and practices helps to build trust at the cost of increasing exposure.

\section{Design issues}

An important part of advancing VEs is the development of conceptual models in which to understand them, akin to the various software lifecycle models. KPN Research presented such an analysis, incidentally highlighting important features of potential VE component organizations. A VE's stability is improved if its components share a partial mission overlap and are not wholly dependent on the VE for their existence. Just as a software lifecycle model views the "finished product" as only one part of an on-going process, the seven-stage prototype VE lifecycle regards the workings of the collaboration as only one phase in its evolution - in many ways a less important phase than the continual strategic modifications needed to make it a success.

The description of a VE is complicated by its dynamism. Andy Wood of DSTC applied some concepts from the RM-ODP Enterprise Viewpoint to modeling VEs. These concepts - such as community, contract and role - do not fit into computational object models, being more closely related to meta-data. The use of roles as "placeholders" for objects allows the population of objects implementing the system to evolve according to an explicitly represented policy. The description of a community of organizations and their interactions may be used as a template for creating instance of a family of related VEs, rather than re-describing them from scratch.

The paper by Mark O'Brien discussed the construction industry and used this to demonstrate that 'virtual enterprises' are alive and well, and that a large part of the world's productive effort is organized in this way. The paper identifies two key characteristics of virtual enterprises; namely, the need for both vertical and horizontal integration within a VE. The form of the argument adopted takes the two key characteristics of 'virtual enterprises' and shows how they are manifested within the construction industry. Given this mapping it is possible to highlight a few of the issues surrounding the existence of 'virtual enterprises' and to show that there may be problems in adopting the approach. The author finished by asking the question: given the (unsolved) 
problems of virtual enterprises, exemplified in the construction industry, do organisations really want to be virtual?

\section{Technological futures}

The WONDA paper addressed the way in which the information architecture of an enterprise determines its strengths and weaknesses. Basically, those architectures rely on wide ranges of data sources that are not completely federated, especially in virtual enterprises. The issues approached in this paper were two-fold. First of all, the authors put the stress on the fact that twotier architectures that had been promoted over the past decade are out-dated. They claim that they should be replaced by $\mathrm{N}$-tier architectures, implemented in their case upon CORBA distributed objects. Nevertheless, because CORBA only addresses distribution, they introduce, in a second part, business objects as a major enhancement for object-oriented distributed infrastructures. They sum up the ways of modeling business objects as well as the need to set up an enterprise wide information server. The discussion leads into the a description of the WONDA architecture which implements the ideas - describing the way IDL specifications are generated for business objects and the way they interact together using a middleware. Their discussion concludes by pointing out that two tier architectures do not adapt well in rapidly changing environments - a fundamental characteristic of VE's.

The second paper addressed presence awareness, a technique to support collaboration in a virtual world, by providing prompts as to the location and current state of a person (i.e. the person is in her room and willing to talk to you). In the context of a virtual enterprise this has important implications. To successfully work with another person ad hoc communication, as well as formal communication, is required. For ad hoc collaboration to happen the presence of the person, or group of people, has to be tangible. In a virtual organisation, a colleague could be in another building, company, or country. Fundamentally, one worker is unable to establish easily the current state of a colleague in another organisation (i.e. are they willing and able to talk to me). The work presented by Lucent elaborated this problem and discussed their solutions to it in the context of a virtual enterprise.

The final paper in the session described the management of component software in a virtual enterprise. The premise on which this is described is that virtual enterprise must customize and integrate software components before individual contributors to the VE can work together. The customization and integration is controlled by events, rules and triggers which express the additional enterprise wide rules which need to be enforced for the VE to work correctly. This is the crux of the contribution of this paper - enterprise rules, which change rapidly and perhaps inconsistently are managed at a high level - adding a layer of flexibility to the underlying technology.

\section{Developing the ideas}

The breakout sessions concentrated on the business driver elements of VEs, since it was felt this was the most promising (and potentially most troublesome) area. The vexed question of what exactly is a VE excited much discussion, as might be expected in such a new field. A number of VEs currently operating within the computer industry (including NIIIP, W3C and OMG) illus- 
trate the point that a VE provides single corporate focus both legally and in terms of a welldefined mission. A VE frequently will strive to hide its "virtuality", presenting the facade of a "standard" enterprise to clients and creditors - although its holdings may be little more that an advisory board and a contact database.

In a rapidly evolving VE the database of contacts, past and future members may be a very important asset - perhaps the most important asset of all. In many ways, the dynamism of the VE will be of only peripheral interest as long as the goals and efficiency of the whole remain stable across changes in its parts. Internally, however, the evolution of the population of the VE may provide critically important management information, for example in terms of which members might be invited into future opportunities (and which should be avoided!).

The economic opportunities of VEs in terms of rapid deployment and "market of one" targeting were considered to be vitally important, although there was little insight as to how a VE might be constructed on such short time-scales. The business community is still very much driven by personal contacts and face-to-face negotiation, which are unlikely to be eliminated by any technical solution. This might be addressed in a number of ways - for example by a set of pre-arranged agreements between potential component companies that can be activated automatically when required. Establishing trust may be aided by leveraging the currently existing professional accreditation schemes. Customer confidence can be increased using techniques such as "private labeling", where an employee of a component organization presents themselves purely as an employee of the VE.

\section{Conclusions}

The four major conclusions of the workshop were:

- Virtual Enterprises are the future embodiment of the Internet and electronic commerce;

- The interplay between business imperatives and technologies in a virtual enterprise is more acute and troublesome than in traditional enterprise information systems;

- Component technology, and supporting design and business methodologies, are vital for the development of virtual enterprises; and

- Expression and management of issues such as trust, naming and negotiation are areas where significant development is needed for virtual enterprises to succeed.

In answering the initial questions of the workshop, the consensus was that the success of virtual enterprises lay in the success of business objects, component integration and the management of both software and people components in the process.

It also identified that orthogonal issues, such as trust management, played a bigger part in the design and implementation of the enterprise components than was first anticipated.

To conclude, the workshop provided a unique forum bringing together an eclectic mix of work which demonstrated the importance of considering the wider picture when designing and building component systems for the virtual enterprise. 


\section{References}

1. Nixon P.A. and Wade V. The Virtues Project, http://www.cs.tcd.ie/Virtues/

2. Dobson, S.A. and Nixon, P.A., The OCVE 98 online proceedings, OOPSLA 98, http://www.cs.tcd.ie/Virtues/ocve98/

3. The OMG Business object domain task force, http://www.omg.org/

4. The Unified Modelling Language, http://www.rational.com/uml/

5. W3C Joint electronic payment initiative, http://www.w3.org/ECommerce/

6. Enterprise Java Beans, http://java.sun.com/

7. CommerceNet's eCo system, http://www.commerce.net/

8. Workflow, http://www.wfmc.org/

9. Jeff Sutherland's Business Object Workshop Series, http://www.jeffsutherland.org/oopsla97/index.html 